\title{
DCP-LA, a New Strategy for Alzheimer's Disease Therapy
}

\author{
Tomoyuki Nishizaki*
}

Innovative Bioinformation Research Organization, 2-3-14 Katsuragi, Kita-ku, Kobe 651-1223, Japan

\section{Article Info}

\section{Article Notes}

Received: September 14, 2017

Accepted: October 12, 2017

\section{${ }^{*}$ Correspondence:}

Dr. Tomoyuki Nishizaki

Innovative Bioinformation Research Organization

2-3-14 Katsuragi, Kita-ku, Kobe 651-1223, Japan, Email: tnishizaki@bioresorganazation.com

(C) 2017 Nishizaki T. This article is distributed under the terms of the Creative Commons Attribution 4.0 International License

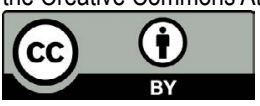

\section{Keywords}

DCP-LA

$\mathrm{PKC} \varepsilon$

Protein tyrosine phosphatase $1 \mathrm{~B}$

Akt

GSK-3 $\beta$

Tau

Alzheimer's disease

\section{ABSTRACT}

Alzheimer's disease $(A D)$ is characterized by extensive deposition of amyloid $\beta(A \beta)$ and formation of neurofibrillary tangles (NFTs) consisting of hyperphosphorylated Tau. So far, a variety of $A D$ drugs targeting $A \beta$ have been developed, but ended in failure. A recent focus on AD therapy, therefore, is development of Tau-targeted drugs. $A \beta$ activates glycogen synthase kinase- $3 \beta$ (GSK-3 $\beta$ ), that plays a central role in Tau phosphorylation, responsible for NFT formation. The linoleic acid derivative DCP-LA has been developed as a promising drug for AD therapy. DCP-LA serves as a selective activator of $\mathrm{PKC} \varepsilon$ and a potent inhibitor of protein tyrosine phosphatase 1B (PTP1B). DCP-LA restrains Tau phosphorylation efficiently due to PKC $\varepsilon$-mediated direct inactivation of GSK- $3 \beta$, to PKC $\varepsilon / A k t-m e d i a t e d$ inactivation of GSK- $3 \beta$, and to receptor tyrosine kinase/insulin receptor substrate 1/phosphoinositide 3-kinase/3phosphoinositide-dependent protein kinase 1/Akt-mediated inactivation of GSK-3 $\beta$ in association with PTP1B inhibition. Moreover, DCP-LA ameliorates spatial learning and memory impairment in 5XFAD transgenic mice, an animal model of AD. Consequently, combination of PKC $\varepsilon$ activation and PTP1B inhibition must be an innovative strategy for AD therapy.

\section{Introduction}

Accumulating evidence has pointed to the role of amyloid $\beta(\mathrm{A} \beta)$, a main body of amyloid (senile) plaques, and Tau protein, a main body of neurofibrillary tangles (NFTs), in the pathogenesis of Alzheimer's disease (AD). Huge studies have been done for development of AD drug targeting $\mathrm{A} \beta$, but no expecting drug has been obtained. Recent target, therefore, has been turned to Tau.

Tau is abundantly expressed in neurons of the central nervous system and stabilizes microtubules by interacting with tubulin. Microtubules are the tracks for motor proteins bearing intracellular transport of vesicles, organelles and protein complexes ${ }^{1,2}$, and Tau modulates microtubule dynamics including axonal transport ${ }^{3-6}$. Tau is upregulated during neuronal development, to promote generation of cell processes and establish cell polarity?

When hyperphosphorylated, Tau detaches from the microtubules and forms fibrils in an insoluble form, referred to as paired helical filaments (PHFs), and NFTs comprises aggregation of PHFs ${ }^{8,9}$. Tau is phosphorylated by a variety of serine/threonine protein kinases such as glycogen synthase kinase-3 $\beta$ (GSK- $3 \beta$ ), cyclin-dependent kinase 5 (Cdk5)/p25, extracellular signal-regulated kinase 2 (ERK2), S6 kinase (S6K), microtubule affinity-regulating kinase (MARK), SAD kinase (SADK), protein kinase A (PKA), calcium/calmodulin-dependent protein kinase II (CaMKII) or Src family kinases such as Fyn and c-Abl (Figure 1) ${ }^{10-14}$. 


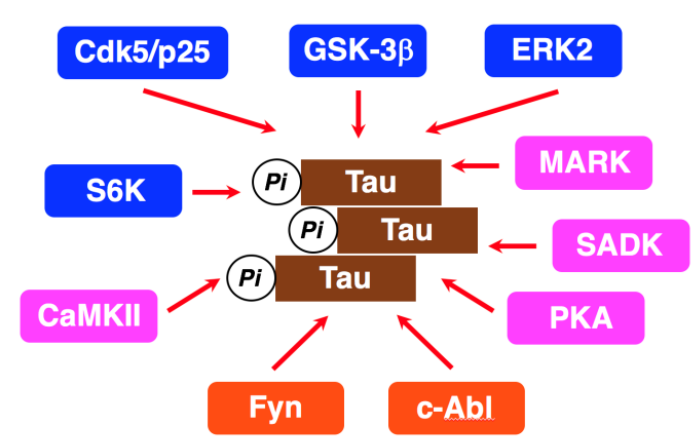

Figure 1: Protein kinases relevant to Tau phosphorylation. The proline-directed kinases GSK-3 $\beta$, Cdk5/p25, ERK2, and S6K and the non-proline-directed kinases MARK, SADK, PKA, and CaMKII phosphorylate Tau at the Ser/Thr residues. The non-receptor tyrosine kinases Fyn and c-Alb phosphorylate Tau at the tyrosine residues.

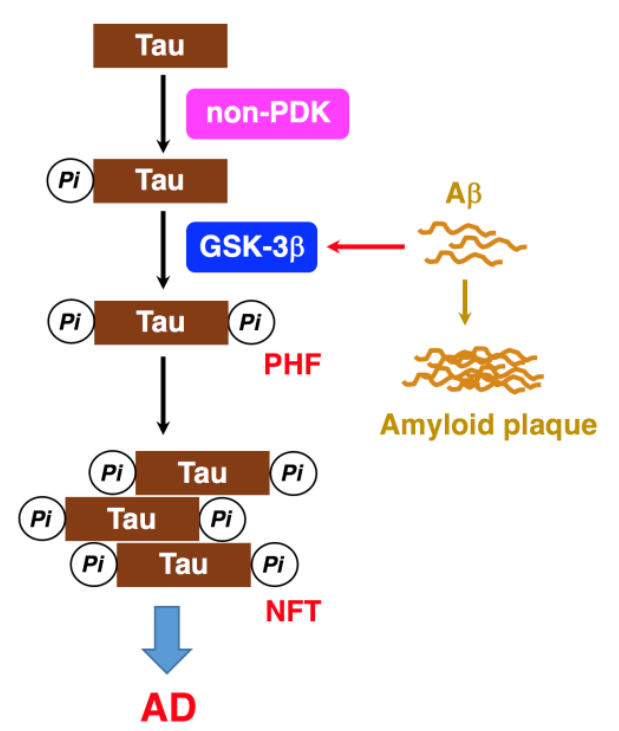

Figure 2: GSK-3 $\beta$ plays a critical role in PHF-Tau phosphorylation. Tau is initially phosphorylated by priming kinases such as nonproline-directed kinases (non-PDK). When GSK- $3 \beta$ activation is enhanced by A $\beta$, GSK-3 $\beta$ accelerates Tau-Ser396 phosphorylation, responsible for PHTs and NHFs, causing AD.

Tau from the AD brain is phosphorylated at eleven Ser/ Thr-Pro and nine Ser/Thr-X sites. Proline-directed kinases such as GSK-3 $\beta$, Cdk5/p25, ERK2, and S6K phosphorylate Tau at Thr181, Ser202/T205, Thr212/S214, Thr231/ Ser235, and Ser396/Ser404 on Ser-Pro or Thr-Pro motifs in the regions flanking the repeat domains ${ }^{10-12}$. Non-prolinedirected kinases such as MARK, SADK, PKA, and CaMKII phosphorylate Tau at Ser262, Ser 320, Ser324, and Ser356 on KXGS motifs in the repeat domains (R1-R4) ${ }^{11,13,14}$. Fyn and c-Abl, on the other hand, phosphorylate Tau at Tyr18 and Tyr394 ${ }^{11}$.

GSK-3 $\beta$ is abundantly expressed in the brain, preferentially in the hippocampus. GSK- $3 \beta$ acts as the main executioner of Tau phosphorylation in
PHFs $^{15,16}$. Intriguingly, GSK-3 accelerates the rate of Tau phosphorylation several-fold, if Tau is pre-phosphorylated by priming kinases such as non-proline-directed kinases ${ }^{17-19}$. Of Tau phosphorylation sites, Ser396 phosphorylation is a key step in the PHF formation ${ }^{20}$. Once a priming kinase phosphorylates Tau at Ser404, GSK-3 $\beta$ phosphorylates Tau at Ser400, followed by sequential phosphorylation of Ser396 (Figure 2) $^{20}$. GSK-3 $\beta$, alternatively, phosphorylates Tau at Ser202 directly, but Thr231 phosphorylation requires for Ser235 pre-phosphorylation ${ }^{20}$.

\section{Interaction between $\mathbf{A} \beta$ and GSK-3 $\beta$}

GSK- $3 \beta$ is originally in the active form. When phosphorylated at Ser9, GSK- $3 \beta$ is inactivated, but when phosphorylated at Tyr216, GSK-3 $\beta$ activation is enhanced ${ }^{21}$.

$\mathrm{A} \beta$ activates the non-receptor tyrosine kinase Fyn, to phosphorylate and activates GSK-3 $\beta$, leading to somatodendritic accumulation of phosphorylated $\mathrm{Tau}^{22}$. $\mathrm{A} \beta_{1-42}$ phosphorylates GSK-3 $\beta$ at Tyr216 and promotes Tau phosphorylation in PC- 12 cells $^{23}$. $\mathrm{A} \beta$, alternatively, activates GSK-3 $\beta$ by decreasing serine phosphorylation as a result of phosphoinositide 3-kinase (PI3K) inhibition/ inactivation $^{24}$. Chronic exposure of $\mathrm{A} \beta$ downregulates Akt phosphorylation, to activate GSK- $3 \beta$ and increase Tau phosphorylation ${ }^{25}$. Soluble $\mathrm{A} \beta$ oligomers inhibit insulin signaling relevant to Akt activation, to activate GSK-3 $\beta$ and increase Tau phosphorylation ${ }^{26}$. Intracellular $\mathrm{A} \beta_{1 \text {. }}$ ${ }_{42}$ promotes Tau phosphorylation and induces neuronal $\operatorname{loss}^{27}$. GSK- $3 \beta$ exacerbates $A \beta$-induced neurotoxicity and cell death ${ }^{28}$.

Amyloid precursor protein (APP) intracellular domain (AICD), that is produced from $\gamma$-secretase-mediated APP cleavage, activates GSK-3 $\beta^{29}$ or enters the nucleus and activates gene transcription, increasing the GSK- $3 \beta$ mRNA and protein ${ }^{30}$. C-terminal fragments of APP stimulate GSK- $3 \beta$ activation, to increase Tau phosphorylation and induce apoptosis ${ }^{31}$.

\section{Regulation of GSK-3 $\beta$ and Tau phosphorylation}

The serine/threonine protein kinases such as $\mathrm{PKC} \varepsilon^{32}$, $\mathrm{Akt}^{32}, \mathrm{PKA}^{33}$, integrin-linked kinase $(\mathrm{ILK})^{34}, \mathrm{CaMKII}^{35}$, p90 ribosomal protein S6 kinase (p90RSK) ${ }^{36}$, and protein kinase C-related kinase 2 (Prk2) ${ }^{37}$ inactivate GSK- $3 \beta$ by directly phosphorylating at Ser9 (Figure 3). Pyk2 ${ }^{38}$, that binds to $\mathrm{SH} 2$ and SH3 domain-containing proteins like Src kinases, and Fyn $^{22}$ activate GSK- $3 \beta$ by phosphorylating at Tyr216 directly (Figure 3).

Akt1 is activated by being phosphorylated at Thr308 and Ser473 through the major pathway along a receptor tyrosine kinase (RTK)/insulin receptor substrate 1 (IRS-1)/PI3K/3phosphoinositide-dependent protein kinase 1 (PDK1)/Akt axis $^{32}$. Then, Akt inactivates GSK-3 $\beta$ by phosphorylating at Ser9 and restrains Tau phosphoryaltion ${ }^{32}$. In the brain, 


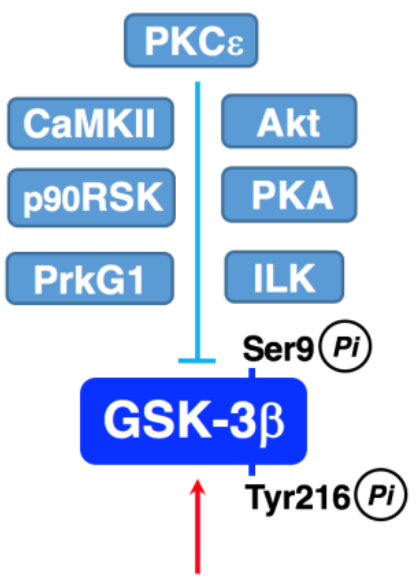

\section{Pyk2 Fyn}

Figure 3: Inactivation and activation of GSK-3 $\beta$. PKC $\varepsilon$, Akt, PKA, ILK, CaMKII, p90RSK, and Prk2 phosphorylate GSK-3 $\beta$ at Ser9 and inactivate GSK-3 $\beta$. Pyk 2 and Fyn phosphorylate GSK-3 $\beta$ at Tyr216 and activate GSK-3 $\beta$.

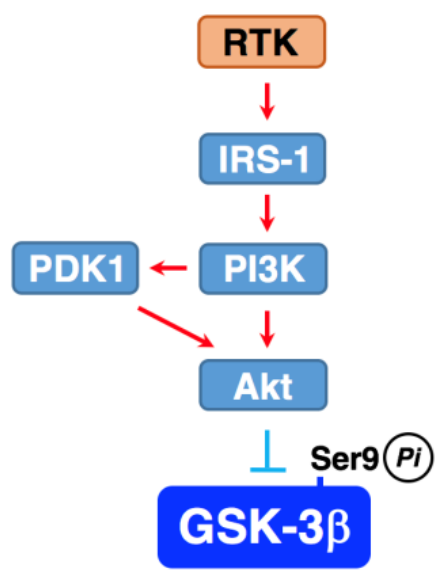

Figure 4: RTK-mediated GSK-3 $\beta$ inactivation. Akt is activated through a pathway along a RTK/IRS-1/PI3K/PDK1/Akt axis and inactivate GSK- $3 \beta$ by phosphorylating at Ser 9 .

insulin or insulin-like growth-factor 1(IGF1) binds to and activates the RTK insulin receptor involving GSK-3 $\beta$ inactivation.

AMP-activated protein kinase (AMPK) is also shown to phosphorylate and inactivate GSK-3 $\beta^{39}$. $\mathrm{A} \beta_{1-42}$ upregulates expression of adenylate kinase-1 (AK1), to inhibit AMPK, thereby leading to GSK-3 $\beta$ activation and Tau phosphorylation ${ }^{40}$. A contradictory finding is that AMPK by itself phosphorylates Tau at Ser262 and induces tauopathy ${ }^{41}$. Moreover, a specific agonist of sphingosine-1phosphate receptor 1 (S1PR1) linked to $\mathrm{G}_{\mathrm{i}}$ protein reduces Tau-Ser262 phosphorylation in rat hippocampal slices ${ }^{42}$. This effect may be caused by AMPK $\alpha$ inactivation due to protein phosphatase 2A (PP2A) activation through a pathway along an S1PR1/G protein/(Cdc42/Rac1)/Pak1/

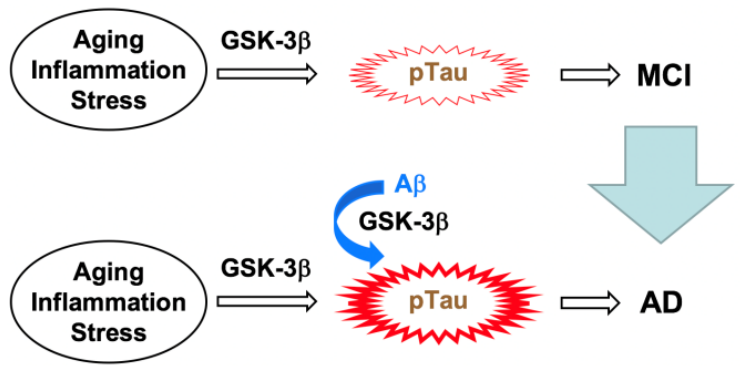

Figure 5: GSK-3 $\beta$ is a key factor for $\mathrm{MCl}$ and AD. Aging, inflammation, and stress activate GSK-3 $\beta$ and phosphorylate Tau, causing $\mathrm{MCl}$. $\mathrm{A} \beta$ enhances GSK-3 $\beta$ activation and accelerates Tau phosphorylation, leading to progression into $A D$ from $\mathrm{MCl}$.

PP2A axis.

Aging, inflammation, and stress activate GSK-3 $\beta$, which triggers Tau phosphorylation, responsible for mild cognitive impairment (MCI), a preliminary group of $\mathrm{AD}$ (Figure 5). A $\beta$ further activates GSK-3 $\beta$ and accelerates Tau phosphorylation, leading to progression into AD from MCI (Figure 5) ${ }^{43,44}$. Aggregation of hyperphosphorylated Tau causes tauopathies, a class of neurodegenerative diseases, that include frontotemporal dementia and parkinsonism linked to chromosome 17, progressive supranuclear palsy, Pick's disease, and corticobasal degeneration as well as AD. Agents that have the potential to suppress GSK-3 $\beta$ activation, thus, could become beneficial preventive and therapeutic drugs for AD.

\section{Tau-targeting drugs}

$\mathrm{A} \beta$ and Tau serve as an initiator and an executor of $\mathrm{AD}$, respectively ${ }^{45}$. Current AD therapeutic approaches focus upon targeting Tau pathologies. A variety of Tau-targeting drugs have been developed as follows: i) Hsp90 inhibitors such as geldanamycin, radicicol, and 17AAG, that degrade and dispose of hyperphosphorylated $\mathrm{Tau}^{46}$, ii) Inhibitors of $\mathrm{A} \beta$-induced Tau phosphorylation such as kamikihito, DHA, and $\operatorname{curcumin}^{47,48}$, iii) Tau aggregation inhibitors such as methylthioninium chloride and leucomethylthioninium, iv) $O$-GlcNAcase inhibitors ${ }^{49}$. Tau is subjected to $O$-GlcNAc transferase-mediated $O$-GlcNAcylation at the Ser/Thr residues, that is the same sites as phosphorylation, and $O$-GlcNAcase neutralizes Tau $O$-GlcNAcylation. $O$-GlcNAcase inhibitors, therefore, promote Tau $O$-GlcNAcylation, thereby preventing Tau phosphorylation and aggregation ${ }^{50}, \mathrm{v}$ ) GSK- $3 \beta$ inhibitors such as pyrazine, the flavonoid morin, MMBO, the thiadiazolidinone derivative NP-12, and the traditional Chinese herbal medicine Angelica sinensis ${ }^{51-55}$, vi) mTOR inhibitors ${ }^{56,57}$. $\mathrm{A} \beta$ activates mTOR, followed by activation of S6K, that phosphorylates TauatSer262,Ser214, and Thr212 ${ }^{12}$. mTOR inhibitors, therefore, could prevent Tau phosphorylation, vii) Inhibitors of Tau fibrillization such as phenothiazine, the cyanine dye N744, polyphenol, porphyrin, anthracyclines, phenylthiazolyl-hydrazide, 
rhodanine, and aminothienopyridazine ${ }^{58,59}$, and viii) microtubule stabilizing agents including natural products such as taxanes, epothilones, discodermolide, dictyostatin, eleutherobin, sarcodyctins, laulimalide, peloruside $\mathrm{A}$, cyclostreptin, taccalonolides, zampanolide, dactylolide, ceratamines, dicumarol, jatrophanes, tubercidin, lutein, and davunetide, and synthetic agents such as GS-164, estradiol analogues, 5HPP-33, triazolopyrimidines, phenylpyrimidines, pyridopyridazines, pyridotriazines, and pyridazines ${ }^{60-62}$. Successful results in the AD therapy, however, have not been obtained with any drugs as yet.

8-[2-(2-Pentyl-cyclopropylmethyl)-cyclopropyl]octanoic acid (DCP- LA)

Several lines of evidence have pointed to the role of cisunsaturated free fatty acids (uFFAs) such as arachidonic, linoleic, linolenic, oleic, and docosahexaenoic acid in cognitive functions ${ }^{63-71}$. Then, one would think that uFFAs might be available as an anti-dementia drug. uFFAs, however, are promptly metabolized and decomposed before arriving in the brain, even though orally or intravenously taken into the body. To address this issue, we have synthesized the linoleic acid derivative DCP-LA with cyclopropane rings instead of cis-double bonds, that exhibits stable bioactivities (Figure $6 \mathbf{A}, \mathbf{B})^{72}$.

DCP-LA induces along-lasting facilitation of hippocampal synaptic transmission by enhancing presynaptic $\alpha 7 \mathrm{ACh}$ receptor responses to stimulate glutamate release under the control of PKC $\varepsilon^{72-75}$. In addition, DCP-LA activates CaMKII due to inhibition of protein phosphatase 1 (PP1), to enhance postsynaptic AMPA receptor responses and facilitate hippocampal synaptic transmission ${ }^{76}$.

The facilitatory action of DCP-LA on hippocampal synaptic transmission accounts for improvement of $\mathrm{A} \beta_{1-40^{-}}$and mutant $\mathrm{A} \beta$-induced spatial learning deficits in rats $^{77,78}$, scopolamine-induced spatial learning and memory disorders in rats $^{77}$, spatial learning and memory deterioration in senescence accelerated mice 8 (SAMP8) ${ }^{79,80}$, and spatial learning and memory impairment in 5xFAD transgenic mice, an animal model of $\mathrm{AD}^{32}$.

$\mathrm{PKC}$ is classified into the conventional PKC isozymes $\alpha, \beta \mathrm{I}, \beta \mathrm{II}$, and $\gamma$, the novel PKC isozymes $\delta, \varepsilon, \eta$, and $\theta$, the atypical PKC isozymes $\iota / \lambda$ and $\zeta$, and the PKC-like isozymes $\mu$ and $\nu$. All the PKCs have the phosphatidylserine (PS) binding site and are activated by diacylglycerol (DG). Much interestingly, DCP-LA is capable of selectively activating PKC $\varepsilon$ in a $\mathrm{Ca}^{2+}$ - and DG-independent manner ${ }^{81}$. DCP-LA binds to the PS binding/associating sites Arg50 and Ile89 in the C2-like domain of $\mathrm{PKC} \varepsilon$, which are distinct from the DG binding site in the C1 domain, at the carboxyl-terminal end and the cyclopropane rings, respectively ${ }^{82}$.

Racemic DCP-LA contains possible 4 diastereomers such as $\alpha, \alpha-, \alpha, \beta-, \beta, \alpha-$, and $\beta, \beta$-DCP-LA (Figure 6C). To develop DCP-LA as a medical drug, each diastereomer was separated and each characteristic was examined. Of 4 diastereomers $\alpha, \beta$-DCP-LA activates PKC $\varepsilon$ selectively and stimulates presynaptic release of glutamate, dopamine, and serotonin, with the highest potency ${ }^{83}$.Of great interest is that DCP-PA serves as not only a selective PKC $\varepsilon$ activator but a potent inhibitor of protein tyrosine phosphatase $1 \mathrm{~B}$ (PTP1B). DCP-LA inhibits PTP1B by its direct interaction ${ }^{84}$.

DCP-LA efficiently inactivates GSK-3 $\beta$ and restrains Tau phosphorylation by cooperation of PKC $\varepsilon$ activation and PTP1B inhibition

PKC $\varepsilon$, activated by DCP-LA, inactivates GSK- $3 \beta$ by directly phosphorylating at Ser9 (Figure 6) ${ }^{32}$. Activated PKC $\varepsilon$, alternatively, activates Akt by directly phosphorylating at the serine residue, followed by inactivation of GSK-3 $\beta$ (Figure 6) ${ }^{32}$.

When activated, RTK phosphorylates its own receptor at Tyr1185 and activates IRS-1 by phosphorylating at Tyr1222. Activated IRS-1 recruits and activates PI3K, which produces phosphatidylinositol 3,4,5-triphosphate ( $\mathrm{PIP}_{3}$ )
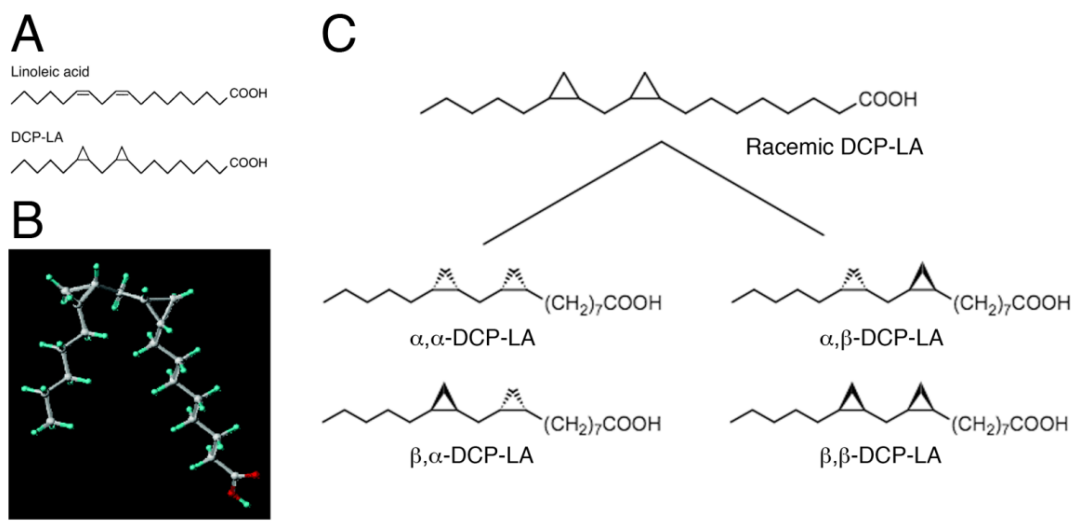

Figure 6: Structure of DCP-LA. DCP-LA has cyclopropane rings instead of cis-double bonds on linoleic acid (A,B). Racemic DCP-LA contains possible 4 diastereomers such as $\alpha, \alpha-, \alpha, \beta-, \beta, \alpha-$, and $\beta, \beta$-DCP-LA (C). 
by phosphorylating phosphatidylinositol 4,5-bisphosphate $\left(\mathrm{PIP}_{2}\right) . \mathrm{PIP}_{3}$ binds to and activates PDK1. PI3K and/or PDK1 activate Akt by phosphorylating at the serine and threonine residues. RTK and IRS-1 are inactivated through PTP1Bmediated tyrosine dephosphorylation. DCP-LA-induced PTP1B inhibition, therefore, represses inactivation of RTK and IRS-1, allowing Akt activation through a RTK/IRS-1/ PI3K/PDK1/Akt pathway, to phosphorylate and inactivate GSK-3 $\beta$ (Figure 6) ${ }^{32}$.

PKC $\varepsilon$ activation or PTP1B inhibition, thus, has the potential to restrain Tau phosphorylation by inactivating GSK-3 $\beta$ each independently. Cooperation of PKC $\varepsilon$ activation and PTP1B inhibition could inactivate GSK- $3 \beta$ and restrain Tau phosphorylation more efficiently than each solitary treatment ${ }^{32}$. In experiments using PC-12 cells, PKC $\varepsilon$ overexpression and PTP1B deficiency activate Akt and inactivate GSK- $3 \beta$ synergistically ${ }^{32}$. A $\beta_{1-42}$ activates GSK- $3 \beta$ by reducing Ser 9 phosphorylation and increases Tau phosphorylation at Ser202/Thr205 and Ser396, and the effects of $\mathrm{A} \beta_{1-42}$ are clearly neutralized by DCP-LA ${ }^{32}$.

$5 x F A D$ mice are widely used as an animal model of AD. 5xFAD mice are APP/presenilin 1 (PS1) double transgenic mice that coexpress five familial forms of $\mathrm{AD}$ mutations such as the Swedish/London/Florida mutations and the M146L/L286V mutations ${ }^{85}$. The $\mathrm{A} \beta_{1-42}$ levels in the $5 \mathrm{xFAD}$ mouse brain increase in an age-dependent manner and spatial memory deficits are induced from 4-5 months of age ${ }^{85}$. The significantly higher levels of GSK-3 $\beta$-Ser9 phosphorylation is also found in the hippocampus of 5xFAD mice from 4-5 months of age as compared with the levels for wild-type control mice, indicating that the GSK- $3 \beta$ activity is enhanced in $5 \mathrm{xFAD}$ mice, possibly in association with $\mathrm{A} \beta_{1-42}$ increase $^{86}$. Moreover, a greater deal of Tau-Ser396 phosphorylation, responsible for PHF formation, is found in the hippocampus of 5xFAD mice ${ }^{86}$. DCP-LA suppresses GSK- $3 \beta$ activation and reduces TauSer396 phosphorylation in the hippocampus of 5xFAD mice to an extent similar to that for wild-type control mice ${ }^{32}$. DCP-LA, thus, enables efficient suppression of Tau-Ser396 hyperphosphorylation by activating $\mathrm{PKC} \varepsilon$ and inhibiting PTP1B simultaneously.

DCP-LA ameliorates spatial learning and memory decline in $5 \mathrm{xFAD}$ mice, that occurs in parallel with GSK- $\beta$ activation and an increase in Tau phosphorylation, but such effect is not obtained with galanthamine, that is clinically used for treatment of mild to moderate $\mathrm{AD}^{32}$. In addition, DCP-LA improves $\mathrm{A} \beta_{1-40^{-}}$and mutant $\mathrm{A} \beta$ induced spatial learning deficits in rats ${ }^{77,78}$, scopolamineinduced spatial learning and memory disorders in rats ${ }^{77}$, spatial learning and memory deterioration in senescence accelerated mice ${ }^{79,80}$. DCP-LA-induced improvement of cognitive decline is not due to only inhibition of GSK- $\beta$ and restraint of Tau phosphorylation. Facilitation of

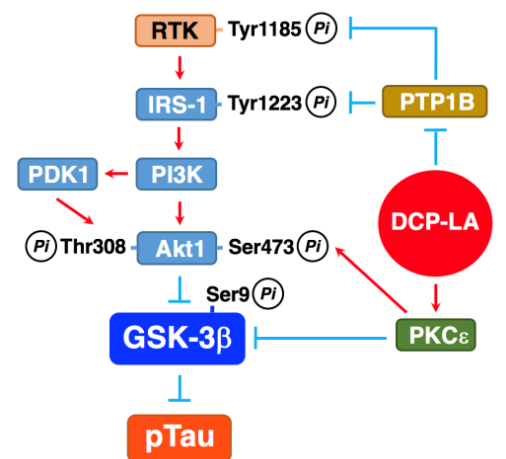

Figure 7: DCP-LA-induced suppression of Tau phosphorylation. PKC $\varepsilon$, activated by DCP-LA, inactivates GSK- $3 \beta$ by phosphorylating Ser9 directly or through a PKCE/Akt pathway, to restrain Tau phosphorylation (pTau). DCP-LA-induced PTP1B inhibition, alternatively, activates Akt through a RTK/IRS-1/PI3K/PDK1/Akt pathway by repressing tyrosine dephosphorylation of RTK and IRS-1, followed by Ser9 phosphorylation and inactivation of GSK-$\beta$, to restrain Tau phosphorylation.

synaptic transmission in alive neurons would be required for improvement of cognitive decline. DCP-LA has the potential to facilitate hippocampal synaptic transmission by enhancing presynaptic $\alpha 7 \mathrm{ACh}$ receptor responses under the control of $\mathrm{PKC} \varepsilon^{72-75}$ and postsynaptic AMPA receptor responses under the control of CaMKII in association with PP1 inhibition ${ }^{76}$. This action of DCP-LA is also a strong advantage as an $\mathrm{AD}$ therapeutic drug as compared with Tautargeted drugs including GSK- $\beta$ inhibitors. Tau-targeted drugs proposed possess no direct facilitatory action on synaptic transmission, and therefore, early improvement of cognitive decline would not be expected by those drugs.

A beneficial effect on 5xFAD mice is obtained with oral administration of DCP-LA at a dose of $1 \mathrm{mg} / \mathrm{kg}$ body weight, corresponding to $\sim 3 \mu \mathrm{M}$. This dose, in the light of the fact that the optimal concentration of DCP-LA in the in vitro experiments is $100 \mathrm{nM}$, seems to be appropriate and possible for clinical use. Overall, DCP-LA may shed a beam of hope on $\mathrm{AD}$ prevention and treatment.

\section{Conclusion}

Tau-targeted drugs for AD therapy under development include i) Hsp90 inhibitors, ii) inhibitors of $A \beta$-induced Tau phosphorylation, iii) Tau aggregation inhibitors, iv) $O$-GlcNAcase inhibitors, v) GSK-3 $\beta$ inhibitors, vi) mTOR inhibitors, vii) inhibitors of Tau fibrillization, and viii) microtubule stabilizing agents. The mechanism underlying the inhibitory effect of DCP-LA on Tau phosphorylation is distinct from that for any drugs provided until now. DCPLA restrains Tau phosphorylation efficiently due to $\mathrm{PKC} \varepsilon$ mediated direct inactivation of GSK- $3 \beta$, to PKC $\varepsilon /$ Aktmediated inactivation of GSK- $3 \beta$, and to RTK/IRS-1/PI3K/ PDK1/Akt-mediated inactivation of GSK- $3 \beta$ in association with PTP1B inhibition. Consequently, combination of PKC $\varepsilon$ 
activation and PTP1B inhibition must be an innovative strategy for AD therapy.

\section{Conflict of Interests Statement}

The author declares no conflict of interests.

\section{References}

1. Hirokawa N, Takemura R. Molecular motors and mechanisms of directional transport in neurons. Nat Rev Neurosci. 2005; 6(3): 201214.

2. Mandelkow E, von Bergen M, Biernat J, et al. Structural principles of tau and the paired helical filaments of Alzheimer's disease. Brain Pathol. 2007; 17(1): 83-90.

3. Garcia ML, Cleveland DW. Going new places using an old MAP: tau, microtubules and human neurodegenerative disease. Curr Opin Cell Biol. 2001; 13(1): 41-48.

4. Binder LI, Guillozet-Bongaarts AL, Garcia-Sierra F, et al. Tau, tangles, and Alzheimer's disease. Biochim Biophys Acta. 2005; 1739(2-3): 216-223.

5. Cuchillo-Ibanez I, Seereeram A, Byers HL, et al. Phosphorylation of tau regulates its axonal transport by controlling its binding to kinesin. FASEB J. 2008; 22(9): 3186-3195.

6. Trinczek B, Ebneth A, Mandelkow EM, et al. Tau regulates the attachment/detachment but not the speed of motors in microtubuledependent transport of single vesicles and organelles. J Cell Sci. 1999; 112(Pt 14): 2355-2367.

7. Drubin DG, Kirschner MW. Tau protein function in living cells. J Cell Biol. 1986; 103(6 Pt 2): 2739-2746.

8. Grundke-Iqbal I, Iqbal K, Tung YC, et al. Abnormal phosphorylation of the microtubule-associated protein $\tau$ (tau) in Alzheimer cytoskeletal pathology. Proc Natl Acad Sci USA. 1986; 83(13): 4913-4917.

9. Brion JP, Couck AM, Passareiro E, et al. Neurofibrillary tangles of Alzheimer's disease: an immunohistochemical study. J Submicrosc Cytol. 1985; 17(1): 89-96.

10. Patrick GN, Zukerberg L, Nikolic M, et al. Conversion of p35 to p25 deregulates Cdk5 activity and promotes neurodegeneration. Nature. 1999; 402(6762): 615-622.

11. Jeganathan S, Hascher A, Chinnathambi S, et al. Proline-directed pseudo-phosphorylation at AT8 and PHF1 epitopes induces a compaction of the paperclip folding of Tau and generates a pathological (MC-1) conformation. J Biol Chem. 2008; 283(46): 32066-32076.

12. Pei JJ, Björkdahl C, Zhang H, et al. p70 S6 kinase and tau in Alzheimer's disease. J Alzheimers Dis. 2008; 14(4): 385-392.

13. Ren QG, Wang YJ, Gong WG, et al. Escitalopram ameliorates Tau hyperphosphorylation and spatial memory deficits induced by protein kinase A activation in Sprague Dawley rats. J Alzheimers Dis. 2015; 47(1): 61-71.

14. Yamamoto $H$, Yamauchi $E$, Taniguchi $H$, et al. Phosphorylation of microtubule-associated protein tau by $\mathrm{Ca}^{2+} /$ calmodulin-dependent protein kinase II in its tubulin binding sites. Arch Biochem Biophys. 2002; 408(2): 255-262.

15. Hernandez F, Lucasa JJ, Avila J. GSK3 and tau: two convergence points in Alzheimer's disease. J Alzheimers Dis. 2013; 33 Suppl 1: S141-144.

16. Imahori K. The biochemical study on the etiology of Alzheimer's disease. Proc Jpn Acad Ser B Phys Biol Sci. 2010; 86(1): 54-61.

17. Singh TJ, Haque N, Grundke-Iqbal I, et al. Rapid Alzheimer-like phosphorylation of tau by the synergistic actions of non-prolinedependent protein kinases and GSK-3. FEBS Lett. 1995; 358(3): 267-272.

18. Cohen P, Frame S. The renaissance of GSK3. Nat Rev Mol Cell Biol.
2001; 2(10): 769-776.

19. Beurel E, Grieco SF, Jope RS. Glycogen synthase kinase-3 (GSK3): regulation, actions, and diseases. Pharmacol Ther. 2015; 148: 114131.

20. Li T, Paudel HK. Glycogen synthase kinase $3 \beta$ phosphorylates Alzheimer's disease-specific Ser396 of microtubule-associated protein tau by a sequential mechanism. Biochemistry. 2006; 45(10) 3125-3133.

21. Forde JE, Dale TC. Glycogen synthase kinase 3: a key regulator of cellular fate. Cell Mol Life Sci. 2007; 64(15): 1930-1944.

22. Li C, Götz J. Somatodendritic accumulation of Tau in Alzheimer's disease is promoted by Fyn-mediated local protein translation. EMBO J. 2017; pii: e201797724.

23. $\mathrm{Hu} \mathrm{M}$, Waring JF, Gopalakrishnan $\mathrm{M}$, et al. Role of GSK-3$\beta$ activation and $\alpha 7$ nAChRs in $A \beta_{1-42}$-induced tau phosphorylation in PC12 cells. J Neurochem, 2008; 106(3): 1371-1377.

24. Takashima A. GSK-3 $\beta$ and memory formation. Front Mol Neurosci. 2012; 5: 47.

25. Abbott JJ, Howlett DR, Francis PT, et al. $A \beta_{1-42}$ modulation of Akt phosphorylation via $\alpha 7 \mathrm{nAChR}$ and NMDA receptors. Neurobiol Aging. 2008; 29(7): 992-1001.

26. Tokutake T, Kasuga K, Yajima R, et al. Hyperphosphorylation of Tau induced by naturally secreted amyloid- $\beta$ at nanomolar concentrations is modulated by insulin-dependent Akt-GSK3 $\beta$ signaling pathway. J Biol Chem. 2012; 287(42): 35222-35233.

27. Rebeck GW, Hoe HS, Moussa CE. $\beta$-Amyloid ${ }_{1-42}$ gene transfer model exhibits intraneuronal amyloid, gliosis, tau phosphorylation, and neuronal loss. J Biol Chem. 2010; 285(10): 7440-7446.

28. Takashima A, Noguchi K, Sato K, et al. Tau protein kinase I is essential for amyloid $\beta$ protein-induced neurotoxicity. Proc Natl Acad Sci USA. 1993; 90(16): 7789-7793.

29. Ryan KA, Pimplikar SW. Activation of GSK-3 and phosphorylation of CRMP2 in transgenic mice expressing APP intracellular domain. J Cell Biol. 2005; 171(2): 327-335.

30. Balaraman Y, Limaye AR, Levey AI, et al. Glycogen synthase kinase $3 \beta$ and Alzheimer's disease: pathophysiological and therapeutic significance. Cell Mol Life Sci 2006; 63(11): 1226-1235.

31. Kim HS, Kim EM, Lee JP, et al. C-terminal fragments of amyloid precursor protein exert neurotoxicity by inducing glycogen synthase kinase-3 $\beta$ expression. FASEB J. 2003; 17(13): 1951-1953.

32. Kanno T, Tsuchiya A, Tanaka A, et al. Combination of PKC $\varepsilon$ activation and PTP1B inhibition effectively suppresses A $\beta$-induced GSK-3 $\beta$ activation and Tau phosphorylation. Mol Neurobiol. 2016; 53(7): 4787-4797.

33. Shelly M, Lim BK, Cancedda L, et al. Local and long-range reciprocal regulation of cAMP and cGMP in axon/dendrite formation. Science. $2010 ; 327(5965): 547-552$.

34. Naska S, Park KJ, Hannigan GE, et al. An essential role for the integrinlinked kinase-glycogen synthase kinase- $3 \beta$ pathway during dendrite initiation and growth. J Neurosci. 2006; 26(51): 13344-13356.

35. Song B, Lai B, Zheng Z, et al. Inhibitory phosphorylation of GSK-3 by CaMKII couples depolarization to neuronal survival. J Biol Chem. 2010; 285(52): 41122-41134.

36. Valerio A, Ghisi V, Dossena M, et al. Leptin increases axonal growth cone size in developing mouse cortical neurons by convergent signals inactivating glycogen synthase kinase-3 $\beta$. J Biol Chem. 2006; 281(18): 12950-12958.

37. Zhao Z, Wang Z, Gu Y, et al. Regulate axon branching by the cyclic GMP pathway via inhibition of glycogen synthase kinase 3 in dorsal root 
ganglion sensory neurons. J Neurosci. 2009; 29(5): 1350-1360.

38. Sayas CL, Ariaens A, Ponsioen B, et al. GSK-3 is activated by the tyrosine kinase Pyk2 during LPA1-mediated neurite retraction. Mol Biol Cell. 2006; 17(4): 1834-1844.

39. Song JS, Kim EK, Choi YW, et al. Hepatocyte-protective effect of nectandrin B, a nutmeg lignan, against oxidative stress: Role of Nrf2 activation through ERK phosphorylation and AMPK-dependent inhibition of GSK-3 $\beta$. Toxicol Appl Pharmacol. 2016; 307: 138-149.

40. Park H, Kam TI, Kim Y, et al. Neuropathogenic role of adenylate kinase- 1 in A $\beta$-mediated tau phosphorylation via AMPK and GSK3 $\beta$. Hum Mol Genet. 2012; 21(12): 2725-2737.

41. Galasso A, Cameron CS, Frenguelli BG, et al. An AMPK-dependent regulatory pathway in tau-mediated toxicity. Biol Open. 2017; pii: bio.022863.

42. St-Cyr Giguère $F$, Attiori Essis $\mathrm{S}$, Chagniel L, et al. The sphingosine1-phosphate receptor 1 agonist SEW2871 reduces Tau-Ser262 phosphorylation in rat hippocampal slices. Brain Res. 2017; 1658: 51-59.

43. Ballatore C, Lee VM, Trojanowski JQ. Tau-mediated neurodegeneration in Alzheimer's disease and related disorders. Nat Rev Neurosci. 2007; 8(9): 663-672.

44. Hurtado DE, Molina-Porcel $L$, Iba $M$, et al. $A \beta$ accelerates the spatiotemporal progression of tau pathology and augments tau amyloidosis in an Alzheimer mouse model. Am J Pathol. 2010; 177(4): 1977-1988.

45. Stancu IC, Ris L, Vasconcelos B, et al. Tauopathy contributes to synaptic and cognitive deficits in a murine model for Alzheimer's disease. FASEB J. 2014; 28(?): 2620-2631.

46. Opattova A, Filipcik P, Cente M, et al. Intracellular degradation of misfolded tau protein induced by geldanamycin is associated with activation of proteasome. J Alzheimers Dis. 2013; 33(2): 339-348.

47. Watari H, Shimada Y, Tohda C. New treatment for Alzheimer's disease, kamikihito, reverses amyloid- $\beta$-induced progression of tau phosphorylation and axonal atrophy. Evid Based Complement Alternat Med. 2014; 2014: 706487.

48. Ma QL, Yang F, Rosario ER, et al. $\beta$-amyloid oligomers induce phosphorylation of tau and inactivation of insulin receptor substrate via c-Jun $\mathrm{N}$-terminal kinase signaling: suppression by omega-3 fatty acids and curcumin. J Neurosci. 2009; 29(28): 9078-9089.

49. Wischik CM, Harrington CR, Storey JM. Tau-aggregation inhibitor therapy for Alzheimer's disease. Biochem Pharmacol. 2014; 88(4): 529-539.

50. Graham DL, Gray AJ, Joyce JA, et al. Increased $O$-GlcNAcylation reduces pathological tau without affecting its normal phosphorylation in a mouse model of tauopathy. Neuropharmacology. 2014; 79: 307-313.

51. Berg S, Bergh M, Hellberg S, et al. Discovery of novel potent and

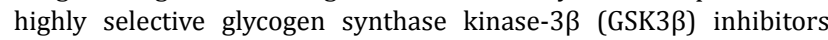
for Alzheimer's disease: design, synthesis, and characterization of pyrazines. J Med Chem. 2012; 55(21): 9107-9119.

52. Gong EJ, Park HR, Kim ME, et al. Morin attenuates tau hyperphosphorylation by inhibiting GSK3 $\beta$. Neurobiol Dis. 2011; 44(2): 223-230.

53. Onishi $\mathrm{T}$, Iwashita $\mathrm{H}$, Uno $\mathrm{Y}$, et al. A novel glycogen synthase kinase-3 inhibitor 2-methyl-5-(3-\{4-[(S)-methylsulfinyl]phenyl\}-1benzofuran-5-yl)-1,3,4-oxadiazole decreases tau phosphorylation and ameliorates cognitive deficits in a transgenic model of Alzheimer's disease. J Neurochem. 2011; 119(6): 1330-1340.

54. Serenó L, Coma M, Rodríguez $M$, et al. A novel GSK-3 $\beta$ inhibitor reduces Alzheimer's pathology and rescues neuronal loss in vivo. Neurobiol Dis. 2009; 35(3): 359-367.

55. Zhang Z, Zhao R, Qi J, et al. Inhibition of glycogen synthase kinase- $3 \beta$ by Angelica sinensis extract decreases $\beta$-amyloid-induced neurotoxicity and tau phosphorylation in cultured cortical neurons. J Neurosci Res. 2011; 89(3): 437-447.

56. Caccamo A, Magrì A, Medina DX, et al. mTOR regulates tau phosphorylation and degradation: implications for Alzheimer's disease and other tauopathies. Aging Cell. 2013; 12(3): 370-380.

57. Caccamo A, Majumder S, Richardson A, et al. Molecular interplay between mammalian target of rapamycin (mTOR), amyloid- $\beta$, and Tau: effects on cognitive impairments. J Biol Chem. 2010; 285(17): 13107-13120.

58. Ballatore C, Brunden KR, Piscitelli F, et al. Discovery of brainpenetrant, orally bioavailable aminothienopyridazine inhibitors of tau aggregation. J Med Chem. 2010; 53(9): 3739-3747.

59. Ballatore C, Brunden KR, Huryn DM, et al. Microtubule stabilizing agents as potential treatment for Alzheimer's disease and related neurodegenerative tauopathies. J Med Chem. 2012; 55(21): 89798996.

60. Brunden KR, Ballatore C, Lee VM, et al. Brain-penetrant microtubulestabilizing compounds as potential therapeutic agents for tauopathies. Biochem Soc Trans. 2012; 40(4): 661-666.

61. Zhang B, Carroll J, Trojanowski JQ, et al. The microtubule-stabilizing agent, epothilone D, reduces axonal dysfunction, neurotoxicity, cognitive deficits, and Alzheimer-like pathology in an interventional study with aged tau transgenic mice. J Neurosci. 2012; 32(11): 36013611.

62. Brunden KR, Yao Y, Potuzak JS, et al. The characterization of microtubule-stabilizing drugs as possible therapeutic agents for Alzheimer's disease and related tauopathies. Pharmacol Res. 2011; 63(4): 341-351.

63. Ikeuchi Y, Nishizaki T, Matsuoka T, et al. Arachidonic acid potentiates ACh receptor currents by protein kinase $\mathrm{C}$ activation but not by receptor phosphorylation. Biochem Biophys Res Commun. 1996; 221(3): 716-721.

64. Nishizaki T, Matsuoka T, Nomura T, et al. Modulation of ACh receptor currents by arachidonic acid. Mol Brain Res. 1998; 57(1): 173-179.

65. Nishizaki T, Nomura T, Matsuoka T, et al. Arachidonic acid as a messenger for the expression of long-term potentiation. Biochem Biophys Res Commun. 1999; 254(2): 446-449.

66. Nishizaki T, Matsuoka T, Nomura T, et al. Arachidonic acid potentiates currents through $\mathrm{Ca}^{2+}$-permeable AMPA receptors by interacting with a CaMKII pathway. Mol Brain Res. 1999; 67(1): 184-189.

67. Nishizaki T, Nomura T, Matsuoka T, et al. Arachidonic acid induces a long-lasting facilitation of hippocampal synaptic transmission by modulating PKC activity and nicotinic ACh receptors. Mol Brain Res. 1999; 69(2): 263-272.

68. Nishizaki T, Ikeuchi Y, Matsuoka T, et al. Short-term depression and long-term enhancement of ACh-gated channel currents induced by linoleic and linolenic acid. Brain Res. 1997; 751(2): 253-258.

69. Nomura T, Nishizaki T, Enomoto T, et al. A long-lasting facilitation of hippocampal neurotransmission via a phospholipase $A_{2}$ signaling pathway. Life Sci. 2001; 68(25): 2885-2891.

70. Nishizaki T, Ikeuchi Y, Matsuoka T, et al. Oleic acid enhances ACh receptor currents by activation of $\mathrm{Ca}^{2+} /$ calmodulin-dependent protein kinase II. Neuroreport. 1997; 8(3): 597-601.

71. Yaguchi T, Yamamoto S, Nagata T, et al. Effects of cis-unsaturated free fatty acids on $\mathrm{PKC}-\varepsilon$ activation and nicotinic ACh receptor responses. Mol Brain Res. 2005; 133(2): 320-324.

72. Tanaka A, Nishizaki T. The newly synthesized linoleic acid derivative FR236924 induces a long-lasting facilitation of hippocampal neurotransmission by targeting nicotinic acetylcholine receptors. Bioorg Med Chem Lett. 2003; 13(6): 1037-1040. 
73. Yamamoto $S$, Kanno $T$, Nagata $T$, et al. The linoleic acid derivative FR236924 facilitates hippocampal synaptic transmission by enhancing activity of presynaptic $\alpha 7$ acetylcholine receptors on the glutamatergic terminals. Neuroscience. 2005; 130(1): 207-213.

74. Kanno T, Tanaka A, Nishizaki T. Linoleic acid derivative DCP-LA stimulates vesicular transport of $\alpha 7 \mathrm{ACh}$ receptors towards surface membrane. Cell Physiol Biochem. 2012; 30(1): 75-82.

75. Kanno T, Tsuchiya A, Tanaka A, et al. The linoleic acid derivative DCP LA increases membrane surface localization of the $\alpha 7 \mathrm{ACh}$ receptor in a protein 4.1N-dependent manner. Biochem J. 2013; 450(2): 303-309.

76. Kanno T, Yaguchi T, Nagata T, et al. DCP-LA stimulates AMPA receptor exocytosis through CaMKII activation due to PP-1 inhibition. J Cell Physiol. 2009; 221(1): 183-188.

77. Nagata T, Yamamoto S, Yaguchi T, et al. The newly synthesized linoleic acid derivative DCP-LA ameliorates memory deficits in animal models treated with amyloid- $\beta$ peptide and scopolamine. Psychogeriatrics. 2005; 5(4): 122-126.

78. Nagata $\mathrm{T}$, Tomiyama $\mathrm{T}$, Mori $\mathrm{H}$, et al. DCP-LA neutralizes mutan amyloid $\beta$ peptide-induced impairment of long-term potentiation and spatial learning. Behav Brain Res. 2010; 206(1): 151-154.

79. Yaguchi T, Nagata T, Mukasa T, et al. Linoleic acid derivative DCP-LA improves learning impairment in SAMP8. Neuroreport. 2006; 17(1): 105-108.
80. Kanno T, Yaguchi T, Shimizu T, et al. 8-[2-(2-Pentyl-cyclopropylmethyl)cyclopropyl]-octanoic acid and its diastereomers improve age-related cognitive deterioration. Lipids. 2012; 47(7): 687-695.

81. Kanno, T. Yamamoto $\mathrm{H}$, Yaguchi $\mathrm{T}$, et al. The linoleic acid derivative DCP-LA selectively activates PKC- $\varepsilon$, possibly binding to the phosphatidylserine binding site. J Lipid Res. 2006; 47(6): 1146-1156.

82. Kanno T, Tsuchiya A, Shimizu T, et al. DCP-LA activates cytosolic PKCe by interacting with the phosphatidylserine binding/associating sites Arg50 and Ile89 in the C2-like domain. Cell Physiol Biochem. 2015; 37(1): 193-200.

83. Shimizu T, Kanno T, Tanaka A, et al. $\alpha$,-DCP-LA selectively activates PKC- $\varepsilon$ and stimulates neurotransmitter release with the highest potency among 4 diastereomers. Cell Physiol Biochem. 2011; 27(2): 149-158.

84. Tsuchiya A, Kanno T, Nagaya H, et al. PTP1B inhibition causes Rac1 activation by enhancing receptor tyrosine kinase signaling. Cell Physiol Biochem. 2014; 33(4): 1097-1106.

85. Oakley $\mathrm{H}$, Cole SL, Logan S, et al. Intraneuronal $\beta$-amyloid aggregates, neurodegeneration, and neuron loss in transgenic mice with five familial Alzheimer's disease mutations: potential factors in amyloid plaque formation. J Neurosci. 2006; 26(40): 10129-40.

86. Kanno T, Tsuchiya A, Nishizaki T. Hyperphosphorylation of Tau at Ser396 occurs in the much earlier stage than appearance of learning and memory disorders in 5XFAD mice. Behav Brain Res. 2014; 274: 302-306. 